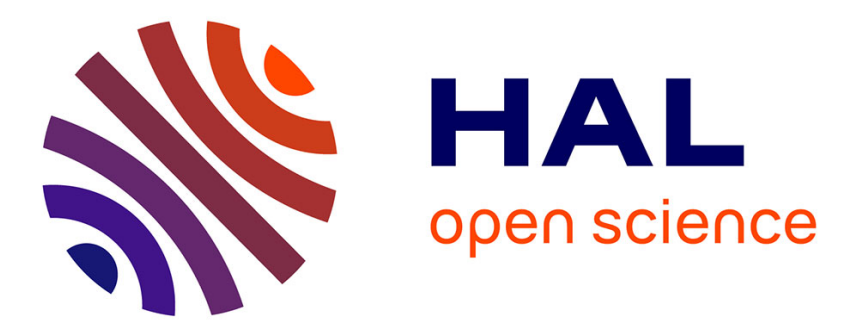

\title{
Precise tailoring of evaporated gold nanocones using electron beam lithography and lift-off
}

\author{
Damien Eschimese, Francois Vaurette, Thierry Melin, S. Arscott
}

\section{To cite this version:}

Damien Eschimese, Francois Vaurette, Thierry Melin, S. Arscott. Precise tailoring of evaporated gold nanocones using electron beam lithography and lift-off. Nanotechnology, 2020, 31 (22), pp.225302. 10.1088/1361-6528/ab746e . hal-02507742

\section{HAL Id: hal-02507742 \\ https://hal.science/hal-02507742}

Submitted on 6 Jan 2021

HAL is a multi-disciplinary open access archive for the deposit and dissemination of scientific research documents, whether they are published or not. The documents may come from teaching and research institutions in France or abroad, or from public or private research centers.
L'archive ouverte pluridisciplinaire HAL, est destinée au dépôt et à la diffusion de documents scientifiques de niveau recherche, publiés ou non, émanant des établissements d'enseignement et de recherche français ou étrangers, des laboratoires publics ou privés. 


\title{
Precise tailoring of evaporated gold nanocones using electron beam lithography and lift-off
}

\author{
Damien Eschimèse ${ }^{1,2}$, François Vaurette ${ }^{1}$, Thierry Mélin ${ }^{1}$ and Steve Arscott ${ }^{1}$ \\ ${ }^{1}$ Institut d'Electronique, de Microélectronique et de Nanotechnologie (IEMN), CN RS, The University of Lille, \\ Cité Scientifique, 59652, Villeneuve d'Ascq, France. \\ ${ }^{2}$ Horiba France SAS, 231 Rue de Lille, 59650, Villeneuve-d'Ascq, France.
}

\begin{abstract}
The ability to fabricate nanocones having precise dimensions is essential for several emerging applications. We demonstrate here a method which can be used to fabricate arrays of gold nanocones with high dimensional precision using lithographic and lift-off means. Electron beam (ebeam) writing of a spin-coated PMMA-based bilayer resist deposited onto silicon wafers is used to form a shadow mask. This mask gradually closes as the deposition of gold (using ebeam evaporation) proceeds - the result is arrays of gold nanocones on the silicon wafer surface after lift-off of the resist. Observations using scanning electron microscopy (SEM) enable a statistical study of the dimensions of 360 gold nanocones - the results demonstrate a high precision of the nanocones dimensions. The fabrication process enables the creation of arrays of nanocones having a base diameter varying from $53.6 \pm 2.1 \mathrm{~nm}$ to $94.1 \pm 2.4 \mathrm{~nm}$, a vertical height ranging from $71.3 \pm 4.1 \mathrm{~nm}$ to $153.4 \pm 3.4 \mathrm{~nm}$, and an apex radius of curvature of ranging from $8.4 \pm 1.2 \mathrm{~nm}$ to $11.6 \pm 1.5 \mathrm{~nm}$. The results are compared with the predictions of a deposition model which considers the evolving shadow masking during the gold deposition to compute the nanocone profile.
\end{abstract}

Keywords: gold nanocones, nanofabrication, electron beam lithography, lift-off, nanostructures 


\section{Introduction}

Technologies involving small, sharp gold nanocones [1-35] are currently of great interest due to their diverse practical applications - ranging from biosensing [2], catalytic surfaces [13], and drug delivery [29] to antireflective coatings [18], surface-enhanced Raman spectroscopy [15], and near-field scanning optical microscopies [10]. The ability to fabricate these structures with precise and accurate dimensions is paramount for the development and amelioration of many of these applications. This is particularly critical for applications harnessing the optical properties of such objects such as near-field probes [10,21,31], optical and photonic surfaces [18], and plasmonic metamaterials [34]; as it is known that the specific nanocone size governs its spectral properties [36-39].

There are several proposed methods in the literature for the manufacture of gold nanocones. These include inter alia masking and etching [14,18,19], maskless etching [23,26], electron beaminduced metal decomposition [28], chemical synthesis [17,25], nanotransfer printing [3], nanoimprint lithography [35], and shadow masking/deposition based techniques [6-8,22,24,30,32]. Concerning the last approach, it is known that combining lithography and evaporation is a powerful method for the fabrication of gold nanocones $[6,7,22,30,32]$. The reasons for this are as follows. The approach is relatively simple to implement and is compatible with planar and other lithographic-based fabrication techniques, e.g. micro/nanoelectromechanical systems (MEMS/NEMS) processes. Consequently, it can be incorporated into a larger technological process. It also enables the fabrication of both accurately positioned isolated nanocones and large, dense arrays of identical nanocones. The technique combines shadow masking [40] during deposition and lift-off techniques [41-43]. Reducing the initial mask opening size by using electron beam lithography $[44,45]$, means that deposited features can have critical dimensions on the nanometre scale [46]. A key feature of this process is the deposition of material onto the mask opening itself, which leads to a gradual reduction of the mask opening as the deposition proceeds - terminating in the complete closing of the mask under certain conditions [47]. The result is a tapered feature, which can have a sharp point if mask closing is fully achieved during the material deposition. Indeed, it has been seen that a variety of resulting feature shapes (ranging from cones and spikes to rings and hollow cylinders) can be produced depending on the mask opening aspect ratio and 
the specific processing conditions-notably sample tilting [30]. Sharp-tipped metallic nanocones, both in isolated form and in arrays, can be manufactured using this approach. However, in most reports very specific dimensions have been sought, therefore no systematic parametric study of the lift-off process or statistical study of the resulting nanocones has been presented. The current paper addresses this issue by demonstrating how the fabrication of small gold nanocones can be precisely tailored using standard ebeam evaporation, electron beam lithography and lift-off means.

\section{Fabrication of gold nanocones using lithography, evaporation, and lift-off}

Figure 1 shows a schematic diagram describing the various steps of the lithographic lift-off process used to fabricate the gold nanocones on silicon wafers. The following sections will describe in detail the individual processes: spin coating, electron beam lithography, and evaporation and lift-off.

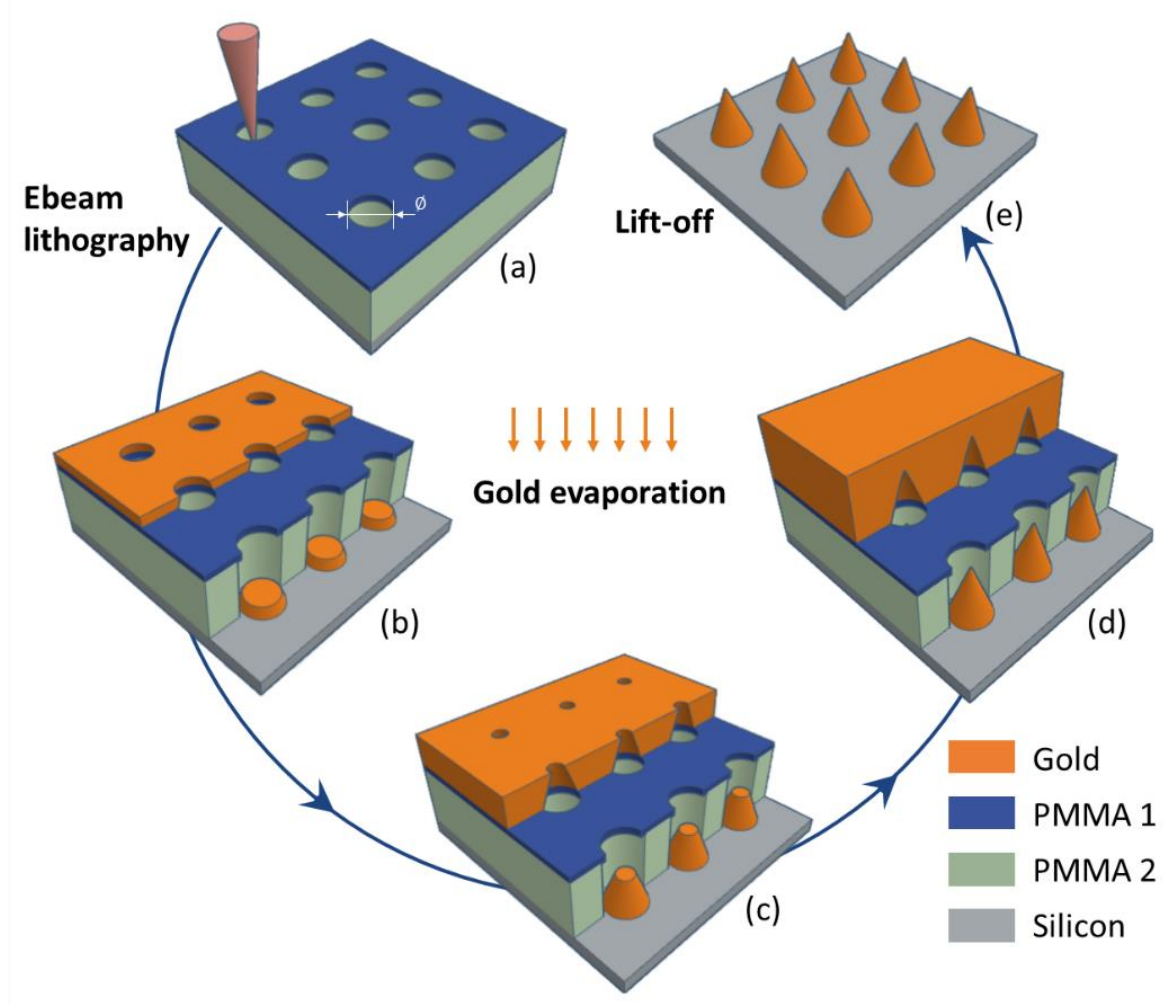


Figure 1. Schematic diagram showing the fabrication of the gold nanocones having a base diameter < $100 \mathrm{~nm}$ using electron beam (ebeam) lithography, gold evaporation, and lift-off. (a) Ebeam writing of the PMMA-based resist bilayer (blue and green) deposited onto a silicon wafer (grey). Subsequent development of the exposed resist defines the diameter of the mask opening. (b) A thin gold mesa is formed at the bottom of the openings at the start of the evaporation. Gold is also deposited onto the mask, leading to a reduction in size of the mask opening. (c) A truncated cone structure is formed as the gold evaporation proceeds and the mask opening gradually reduces. (d) A nanocone is formed when the mask opening is fully closed. Further evaporation onto the mask surface has no effect on the nanocone dimensions. (e) Lift-off of the unexposed resist in a suitable solvent reveals the nanocones adhered to the silicon surface.

\subsection{Spin coating of the bilayer resist}

3-inch diameter (100) silicon wafers (Siltronix, France) were purchased for the study. Prior to processing, they are cleaned using an RCA procedure [48]. The wafer surfaces are then dehydrated on a hotplate $\left(180^{\circ} \mathrm{C} / 10\right.$ minutes $)$. Following this, a bilayer electron beam sensitive resist is spin coated (RC8, SÜSS MicroTec SE) onto the wafer surfaces to create the overhang and undercut features necessary for a lift-off process [30]. The resists are positive tone to an electron beam. The first resist layer is a copolymer methyl methacrylate-methacrylic acid P(MMA-MAA 8.5\%) ethyl lactate (EL) 13\% (MicroChem, USA) and is deposited by spin-coating at $4000 \mathrm{rpm} / 1000 \mathrm{rpm} \mathrm{s}^{-1}$ for 12 seconds to obtain a $450 \mathrm{~nm}$ thick film. An initial homogenization spin coating step (500 rpm/1000 rpm s${ }^{-1} / 6$ seconds) was performed. Pre-baking of the resist is performed in two steps to reduce the effects of potential thermal shock $\left(1\right.$ minute at $80^{\circ} \mathrm{C}$ followed by 10 minutes at $\left.180^{\circ} \mathrm{C}\right)$. A second resist layer is poly(methyl methacrylate) (PMMA) 950K diluted 5/3 with Anisole (MicroChem, USA) and deposited using spin coating onto the first $\mathrm{P}(\mathrm{MMA}-\mathrm{MAA})$ based resist. This second resist layer will create the overhang feature. The second resist layer is spin coated at $4000 \mathrm{rpm} / 1000 \mathrm{rpm} \mathrm{s}^{-1}$ for 12 seconds to obtain a thickness of $50 \mathrm{~nm}$. Again, an initial homogenization step (800 rpm/1000 rpm s $\mathrm{s}^{-1} / 8$ seconds) is performed. The second resist is also pre-baked for 1 minute at $80^{\circ} \mathrm{C}$ followed by 10 minutes at $180^{\circ} \mathrm{C}$. 


\subsection{Electron beam lithography and resist development}

The bilayer resist is then written using electron beam lithography chamber (Raith EBPG 5000

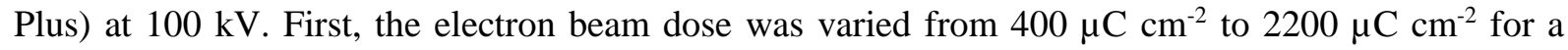
circular mask feature having a fixed diameter. Second, this optimum dose is applied to write several circular mask features having varying diameters. The mask design (GDSII file) was created using LayoutEditor software (Juspertor GmbH, Germany). The mask design contained circles having diameters ranging from $24 \mathrm{~nm}$ to $50 \mathrm{~nm}$. The mask also includes larger shapes (square-shaped micrometre-sized openings) near to the nanocones to promote the lift-off process by allowing the developer solution to dissolve the unexposed resist. If such shapes are not included, the lift-off can take a considerable amount of time. These larger shapes also help identifying the position of the mask openings and the eventual nanocone arrays scanning electron microscopy is performed. In order to fracture the GDSII file, BEAMER software (GenISys GmbH) was used. A proximity file correction (PMMA on Silicon) was used — the resolution was $5 \mathrm{~nm}$ for the dose test, and $1 \mathrm{~nm}$ for the features with varying diameters (as we will discuss in section 4.2). A chemical development of the resist bilayer is performed to remove the exposed part of the resist and form the overhang and undercut features required for the later lift-off step. The exposed resist bilayer is developed for 60 seconds using a mixture of VLSI grade methyl isobutyl ketone (MIBK) and isopropyl alcohol (IPA) with a volume ratio $v / v=1 / 2$.

\subsection{Metal deposition using evaporation and lift-off procedure}

The wafers are then rinsed in pure IPA and dried with dry nitrogen. The PMMA-based patterned silicon wafers are then loaded into a MEB 550S electron beam evaporation system (Plassys, France) at $<10^{-7} \mathrm{mbar}$ for a chromium/gold deposition using planetary-rotated (5.2 rpm), electron beam evaporation. A $5 \mathrm{~nm}$ thick adhesion layer [49] of chromium is first deposited at $\sim 0.2 \mathrm{~nm} \mathrm{~s}^{-1}$. Following this, a $250 \mathrm{~nm}$ thick gold layer is deposited onto the patterned wafer at two calibrated deposition rates $v$ 
$\left(0.2 \mathrm{~nm} \mathrm{~s}^{-1}\right.$ and $\left.1 \mathrm{~nm} \mathrm{~s}^{-1}\right)$ in order to observe the effect of this parameter on the resulting nanocone dimensions. The error of the orthogonality of the wafers with respect to the evaporation source is $\pm 0.5^{\circ}$.

The evaporated wafers are removed from the evaporator and a lift-off procedure is conducted. This consists of removing the bilayer resist using an n-methyl-2-pyrrolidone 'Remover PG' (Microchem, USA) bath at $70^{\circ} \mathrm{C}$ for 120 minutes. To finish the process, the samples are rinsed in acetone and IPA (several minutes) and dried using dry nitrogen. The resulting gold nanocones were observed using scanning electron microscopy.

\section{SEM observation and measurement of nanocone dimensions}

The gold nanocones are observed using scanning electron microscopy (SEM) using an Ultra-55 (Zeiss, Germany). The lithographic masking used here allowed arrays of nominally identical nanocones to be patterned onto multiple silicon wafers. This enables a statistical study of the precision of: (i) nanocones on the same wafer which have undergone the same processes and (ii) nanocones from waferto-wafer, where the same technological process is intended. Indeed, it should be noted that what we mean when referring to 'precision' in the current manuscript is related to the reproducibility (nanocones on the same wafer) and repeatability (nanocones on different wafers having undergone the same technological process).

The observation of the samples in the scanning electron microscope is undertaken using an inhouse manufactured mechanical sample holder which allows the silicon wafer (containing the gold nanocones) to be orientated perpendicularly to the SEM sample holder. This configuration facilitates SEM observations to be made when the silicon wafer has been cleaved and nanocone arrays are situated in proximity to the cleaved wafer edge-Figure 2 shows an example of this. 


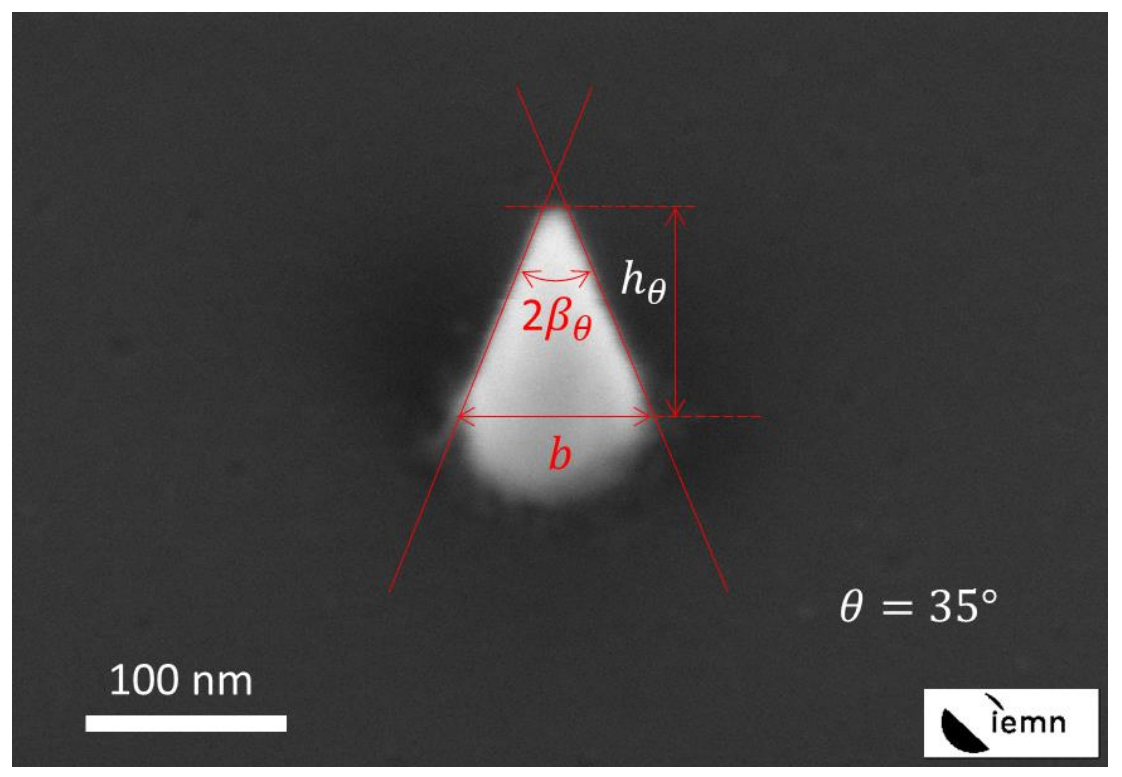

Figure 2. An example of the scanning electron microscopy (SEM) observation of the gold nanocones using inclined SEM observation. The SEM inclination angle is $35^{\circ}$ in this case. The apparent tilted nanocone height $h_{\theta}$ and apparent half-angle $\beta_{\theta}$ are indicated in the figure. The real nanocone base dimeter is $b$.

The following passage explains how the nanocone dimensions $b$ (cone base diameter), $h$ (nanocone vertical height), and $r$ (nanocone tip radius) are obtained from the SEM images. These are important dimensions to be able to control for applications - let us recall that the physical dimensions of the nanoparticle, such as a nanocone here, are known to determine its spectral properties [36]. In addition, the aspect ratio of a nanoparticle is an important parameter which can govern the shift of the plasmonic resonance [37].

First, an image of each nanocone is captured at a certain SEM inclination angle $\theta$-an example is given in Fig. 2. This image is analysed using software [50] to extract the value of the base diameter $b$, the apparent nanocone height under inclination $h_{\theta}$, and the apparent apex half-angle under inclination $\beta_{\theta}$. This latter value is extracted from the images by fitting two straight lines to the nanocone sides. These two lines intersect at a distance above the tip of the nanocone. Remembering that $h_{\theta}$ and $\beta_{\theta}$ are 
apparent values due to the wafer inclination, the following equations allow one to obtain $h$ and $\beta$ of the cone:

$$
\begin{gathered}
h=\frac{h_{\theta}}{\cos \theta} \\
\beta=\tan ^{-1}\left(\tan \beta_{\theta} \cos \theta\right)
\end{gathered}
$$

These three values $(b, h$, and $\beta$ ) now allow one to calculate the nanocone tip radius-if, in a first approximation, we assume that the tip of the nanocone is circular-and that the structure is a perfectly conical shape up to the circular tip. The following passage will describe this.

With reference to Figure 3, simple trigonometry can be used to obtain the following equation for the circular tip radius $r$ of the nanocone in terms of the half-angle $\beta$ of the nanocone, the nanocone base diameter $b$, and the nanocone vertical height $h$ :

$$
r=\frac{\sin \beta}{1-\sin \beta}\left(\frac{b}{2 \tan \beta}-h\right)
$$

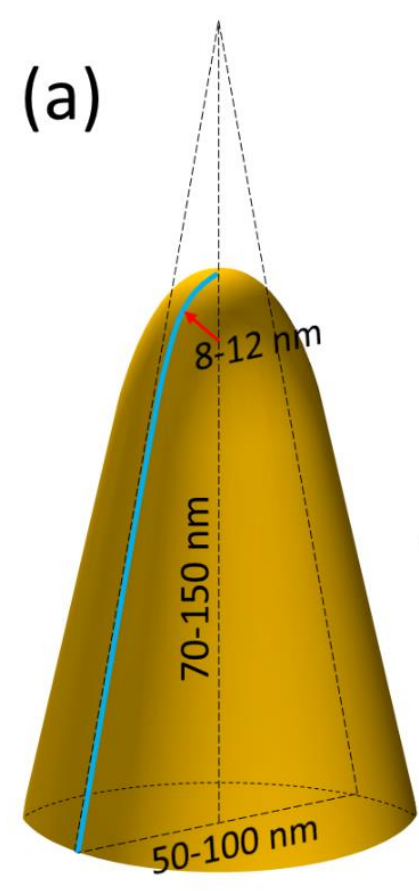

Gold nanocone

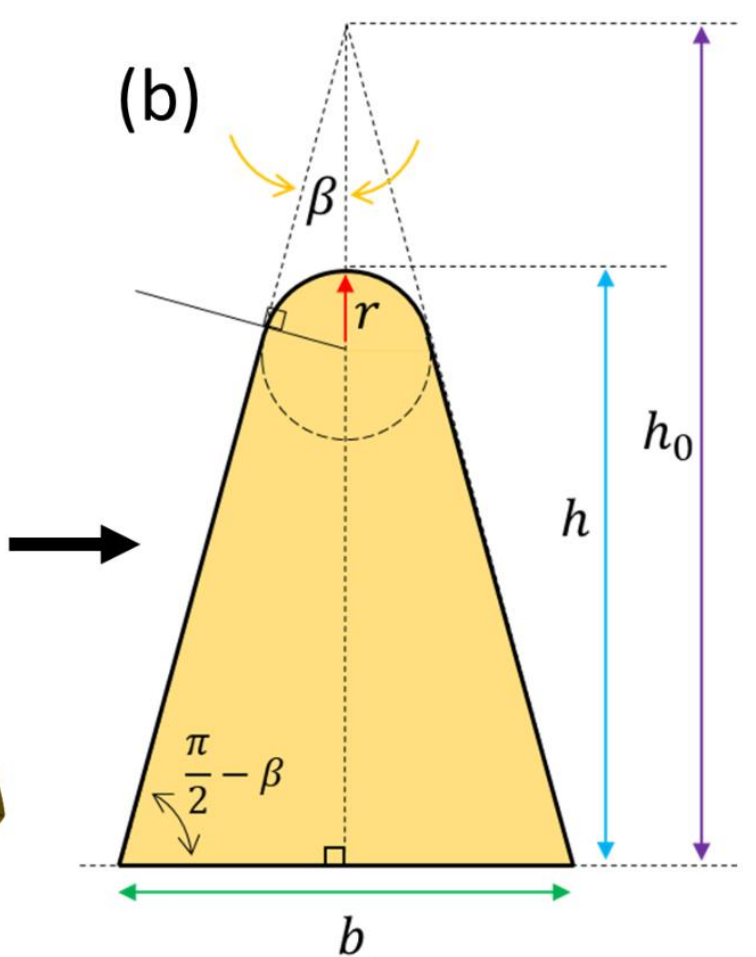


Figure 3. (a) A 3D schematic diagram of a gold nanocone. (b)The geometrical parameters used to calculate the tip radius of the nanocone. The blue line in the Fig. 3(a) shows where the vertical crosssection is taken to produce Fig. 3(b). In Fig. 3(b), the base $b$ (green arrow), the height $h$ (blue arrow), and the tip radius $r$ (red arrow) characterize the nanocone. The half-angle $\beta$ (orange arrows) is shown at the apex of the perfect nanocone having height $h_{0}$ (purple arrow).

Analysis of the SEM data using the method described above allows us to plot the data which will be presented in the following section.

\section{Results and comparison with modelling of the deposition}

\subsection{Effect of electron beam dose for single mask feature}

An initial study was performed to estimate the optimum ebeam dose for nanocone fabrication using a PMMA-based bilayer resist thickness equal to $450 \mathrm{~nm} / 50 \mathrm{~nm}$. In order to do this, the ebeam dose was varied from $400 \mu \mathrm{C} \mathrm{cm}^{-2}$ to $2200 \mu \mathrm{C} \mathrm{cm}^{-2}$ whilst employing a $30 \mathrm{~nm}$ diameter ebeam pattern. Using this method, large arrays of nanocones of differing ebeam doses could be fabricated and studied. SEM imaging of the nanocone arrays enables two pieces of information to be extracted. First, the 'nanocone yield' which we evaluated from the presence or not of a nanocone. Second, the dimensional reproducibility of the resulting metallic nanocones using the process.

Concerning the nanocone yield, it was observed that the ebeam dose range $1200-1800 \mu \mathrm{C} \mathrm{cm}^{-2}$ results in a yield of approximately $100 \%$. Outside this dose range the yield falls - this is especially apparent at ebeam doses $<1200 \mu \mathrm{C} \mathrm{cm}^{-2}$ because the dose is not high enough to completely open the resist during the subsequent development step. The ebeam dose determines the developed resist lift-off profile. A dose which is too low or too high can result in the openings and overhangs of the lift-off profile not be correctly defined — this can lead to the poor yield observed. 
In terms of dimensional reproducibility, it was observed that the dose range $1200-1800 \mu \mathrm{C} \mathrm{cm}^{-}$ ${ }^{2}$ enables the fabrication of nanocone features having reproducibly precise dimensions. Figure 4 shows plots of nanocone height, base diameter, half-angle, and aspect ratio obtained from the SEM observations. 130 nanocones were measured for this part of the study, i.e. $~ 16$ nanocones measured per data point. The mean and standard deviation was calculated for each data point. Based on the observed nanocone yield and the dimensional reproducibility obtained in this part of the study, an ebeam dose of $1500 \mu \mathrm{C} \mathrm{cm} \mathrm{cm}^{-2}$ was used in the following study — which had the objective of examining the effect of changing the ebeam mask design diameter on the resulting nanocone dimensions.
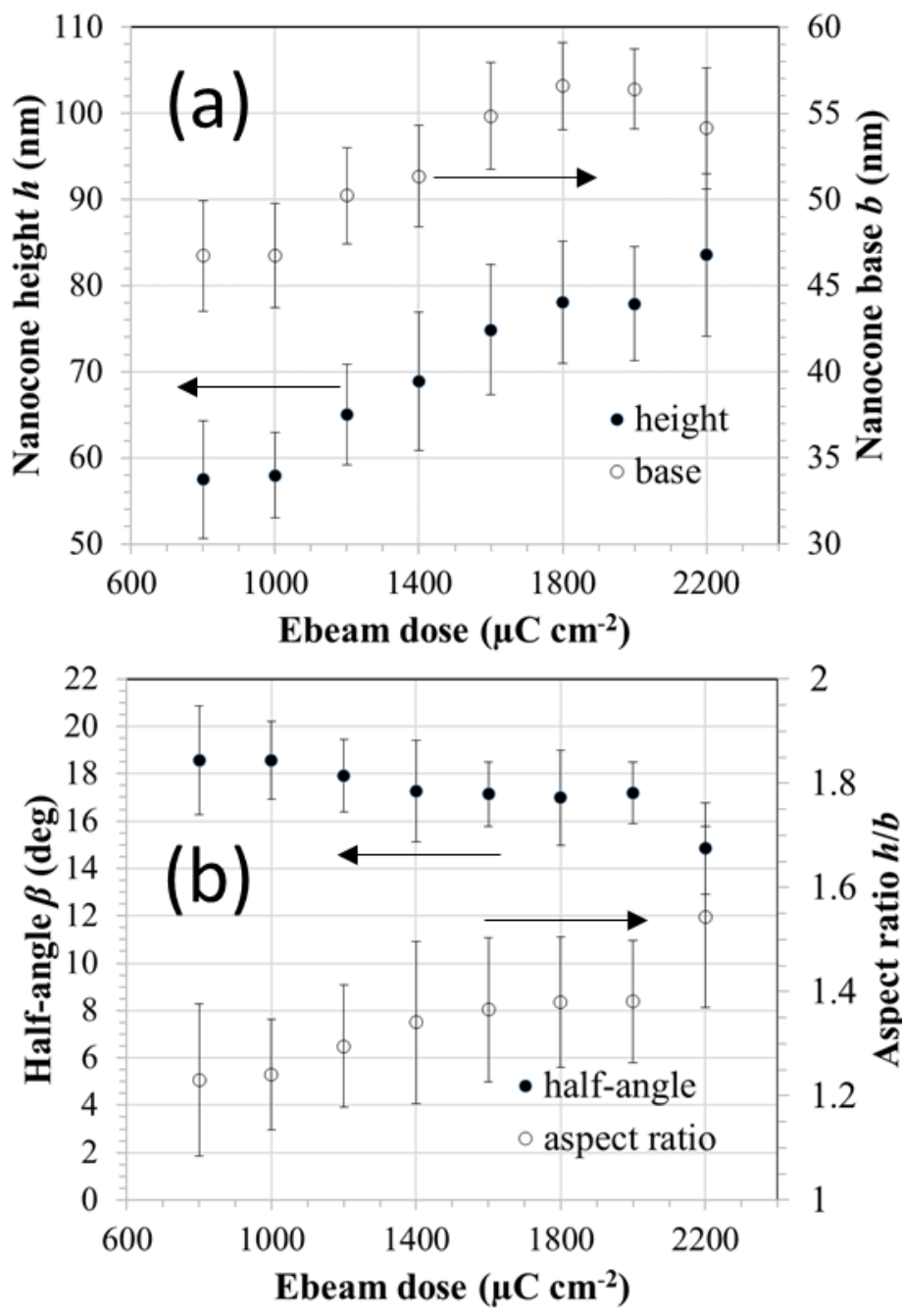

Figure 4. Principle nanocone dimensions obtained from the ebeam dose study. (a) Nanocone height $h$ (filled circles) and base diameter $b$ (open circles) as a function of electron beam lithographic dose. (b) 
Nanocone half-angle $\beta$ (filled circles) and the nanocone aspect ratio $(h / b)$ (open circles) as a function of electron beam lithographic dose. 130 gold nanocones were analysed to obtain the data, i.e. 16 nanocones per data point. The ebeam mask diameter was $30 \mathrm{~nm}$ and the resolution used to fracture the circle was $5 \mathrm{~nm}$.

\subsection{Effect of mask diameter at constant electron beam dose}

In this part of the study the ebeam dose is kept constant $\left(1500 \mu \mathrm{C} \mathrm{cm}{ }^{-2}\right)$ and the ebeam mask diameter is varied in the range $24-50 \mathrm{~nm}$ with a step of $2 \mathrm{~nm}$. As above, the lithography, evaporation, and lift-off process enabled the fabrication of silicon surfaces containing arrays of nanocones as a function of mask diameter. 200 metallic nanocones were measured for this part i.e. $\sim 10$ nanocones measured per data point. In order to observe the effect of deposition rate $v$ on the resulting cones, two deposition rates were employed during the evaporation of the gold: $v=1 \mathrm{~nm} \mathrm{~s}^{-1}$ and $v=0.2 \mathrm{~nm} \mathrm{~s}^{-1}$.

The scanning electron microscopy images in Figure 5 show examples of the gold nanocones fabricated for this part of the study. First, concerning the overall shape of the resulting nanocones, it is apparent that the gold nanocones are not perfect geometrical conical structures. The base of the nanocones is rounded (negative curvature) and the apex of the nanocone is not a perfect point (positive curvature). However, the sidewalls of the nanocones are very straight. Second, the SEM imaging often indicates what appears to be a metallic 'residue' in proximity to the base of the nanocone. (This is seen in the literature [6]) The contrast of the SEM suggests that this residue is gold. Using the methodology described above in Section 3 one can extract the relevant values from the nanocone SEM images.

Figure 6 shows plots of the various nanocone dimensions obtained from the analysis of the SEM images. These are the base diameter $b$ as a function of ebeam mask diameter [Fig. 6(a)], vertical height $h$ as a function of base diameter $b$ [Fig. 6(b)], nanocone aspect ratio $(h / b)$ as a function of $b$ [Fig. 6(c)], tip radius $r$ as a function of $b$ [Fig. 6(d)]. In some cases, the extracted data can be fitted using a linear least squares approach. These are the black dashed lines on the graphs in Figure 6. This fitting of the data allows the following equations to be written down for the nanocone dimensions. At $v=1 \mathrm{~nm} \mathrm{~s}^{-1}$ 
we have $h=2.08 b-41.28$ and $h / b=7.91 \times 10^{-3} b-0.884$. At $v=0.2 \mathrm{~nm} \mathrm{~s}^{-1}$ we have $h=1.84 b-$ 16.83. The linear fit for the aspect ratio is not given as the coefficient of determination is far from unity.

The experimental half-angle $\beta$ (not shown) varies very little from $15^{\circ}$ to $14.7^{\circ}$ as $b$ increases.

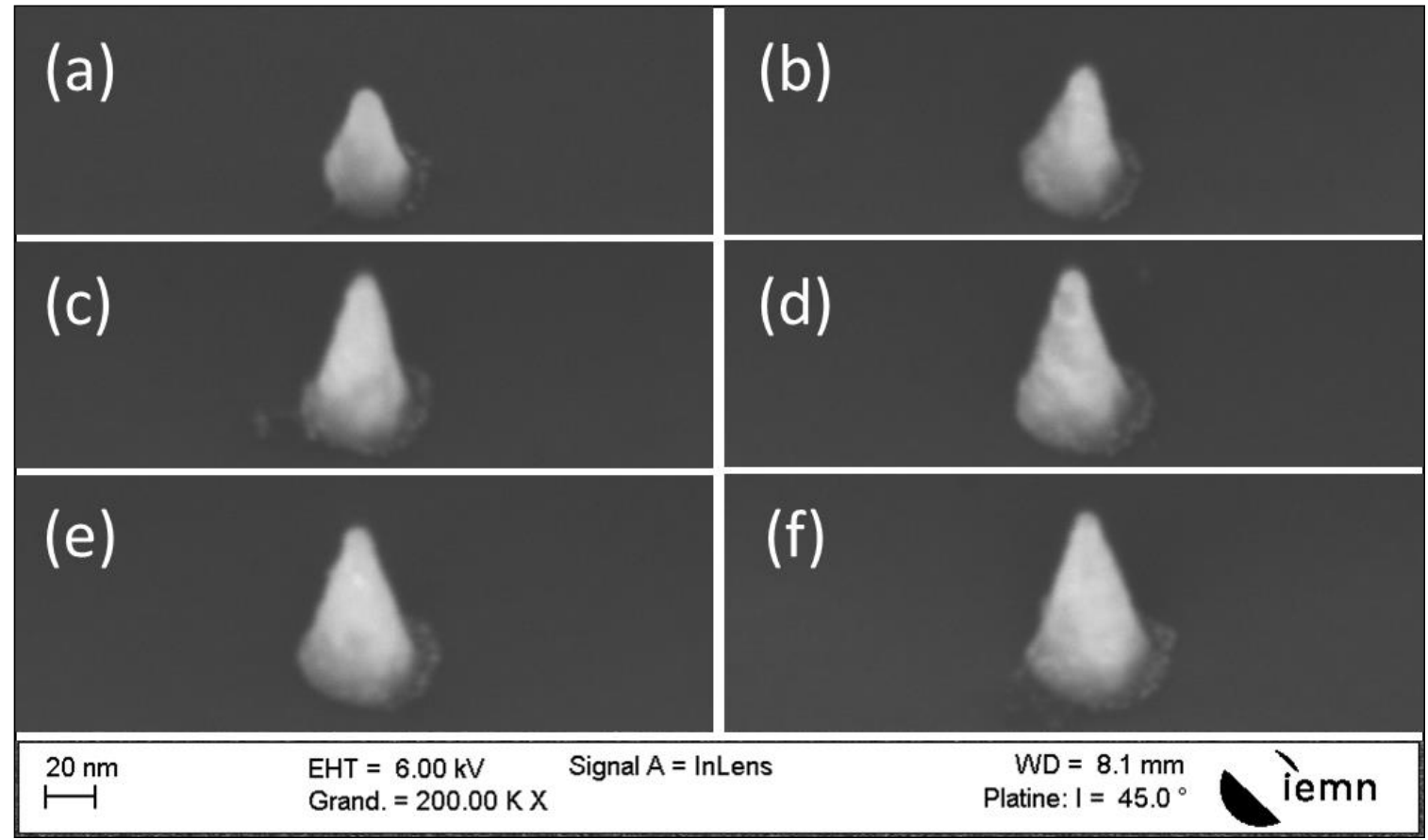

Figure 5. Scanning electron microscopy images of gold nanocones fabricated using electron beam (ebeam) lithography of a PMMA-based bilayer resist, evaporation, and lift-off techniques. The base diameters $b$ of the nanocones are: (a) $67 \mathrm{~nm}$, (b) $75 \mathrm{~nm}$, (c) $81 \mathrm{~nm}$, (d) $85 \mathrm{~nm}$, (e) $88 \mathrm{~nm}$, and (f) $94 \mathrm{~nm}$. The bilayer resist is composed of P(MMA-MAA)/PMMA (450 nm/50 nm). The ebeam dose employed is $1500 \mu \mathrm{C} \mathrm{cm}^{-2}$. The pattern size on the mask was $32 \mathrm{~nm}, 38 \mathrm{~nm}, 42 \mathrm{~nm}, 44 \mathrm{~nm}, 46 \mathrm{~nm}$, and $50 \mathrm{~nm}$ respectively. The gold deposition rate is $1 \mathrm{~nm} \mathrm{~s}^{-1}$. 

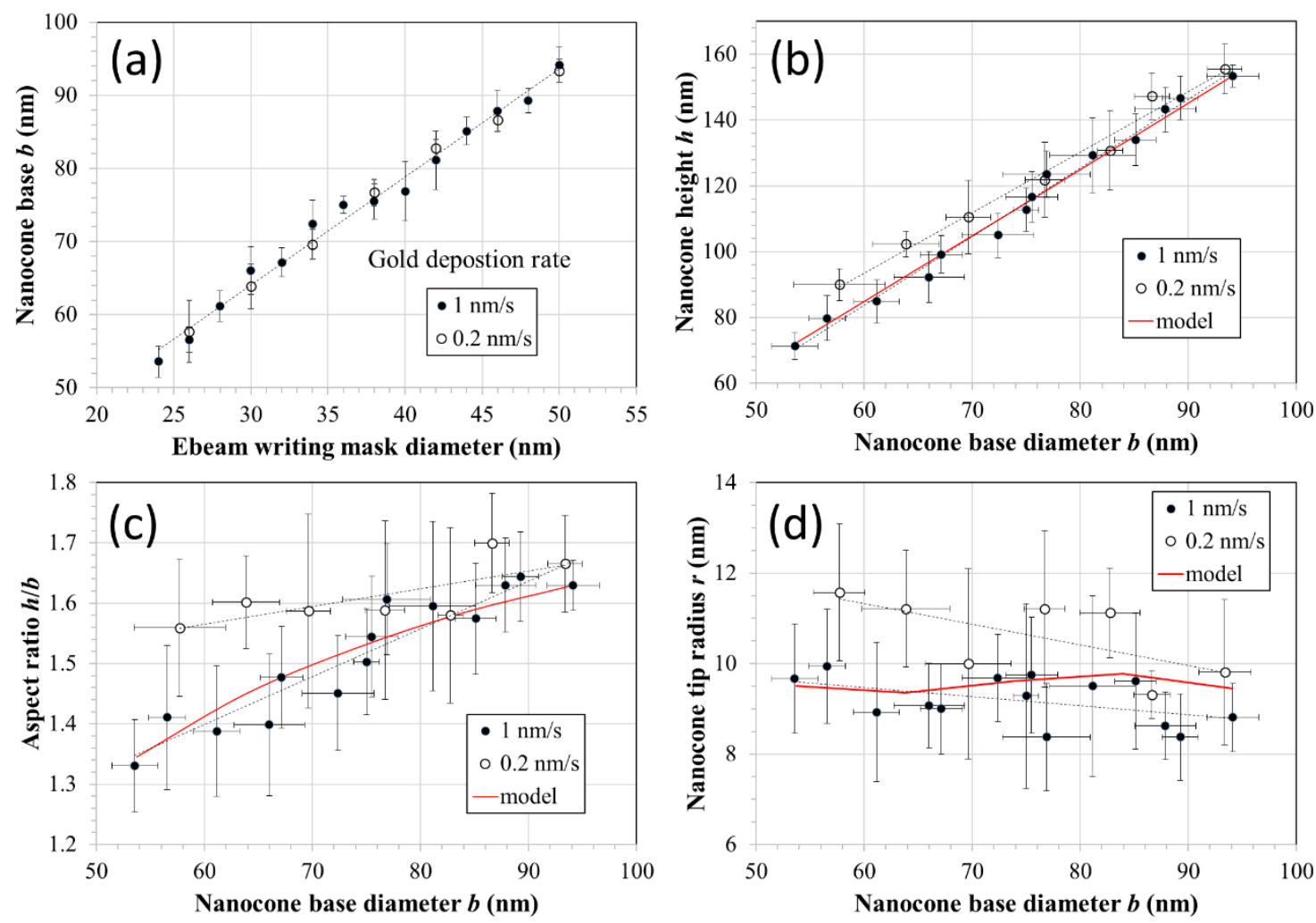

Figure 6. Nanocone dimensions as a function of mask size and gold evaporation rate. (a) Nanocone base diameter $b$ versus electron beam writing mask diameter $d$. (b) Nanocone vertical height $h$ versus $b$. (c) Nanocone aspect ratio $(h / b)$ versus $b$. (d) Nanocone tip radius $r$ versus $b$. The gold was evaporated at two different rates: $0.2 \mathrm{~nm} \mathrm{~s}^{-1}$ (open circles) and $1 \mathrm{~nm} \mathrm{~s}^{-1}$ (filled circles). In all cases, the electron beam areal dose is $1500 \mu \mathrm{C} \mathrm{cm}^{-1}$ and the resolution used to fracture the circles was $1 \mathrm{~nm}$. The error bars are values of standard deviation calculated from 200 nanocones i.e. $~ 10$ nanocones per datapoint. The black dashed lines show linear fits to the data. The red solid line shows the results of the modelling [47].

Concerning evaporated gold nanocones fabricated using comparable lift-off methods, Kontio et al [7] fabricate highly conic-like features having a base diameter of $130 \mathrm{~nm}$ and a height of $257 \mathrm{~nm}-$ i.e. an aspect ratio $h / b \sim 2$. Liu et al [24] fabricated sub-100 $\mathrm{nm}$ diameter gold nanocones — but with much lower aspect ratios $(h / b \sim 0.2-0.5)$ using evaporation via a shadow mask. The range of heights of the nanocones fabricated here are comparable to those fabricated by Chang et al [15] for SERS applications - in contrast, the lift-off process used here is easier to integrate into a larger fabrication 
process. Kim et al [3] fabricated gold nanocones having base diameters and heights equal to $100 \mathrm{~nm}$ and $270 \mathrm{~nm}(h / b=2.7)$ - noting that the gold deposition rate had an effect on the nanocone shape, as is observed here - they attributed this to the dependence of the conformal coverage on the deposition rate [51]. Using evaporation and shadow masking techniques, Fulmes et al [32] fabricated gold nanocones and conducted a statistical study of the resulting dimensions. They report a height of $91 \pm 6 \mathrm{~nm}$ and a non-circular base having dimensions of $46 \pm 5 \mathrm{~nm}$ and $54 \pm 2 \mathrm{~nm}$ - quoting an aspect ratio of 1.85 .

Nanocones fabricated using other materials [52-70] e.g. other metals [62], silicon [60], carbon [59], boron nitride [58], aluminium nitride [54], titanium dioxide [67] and processes are also of great interest for a wide range of applications. The process demonstrated here could, in principle, be applied for the fabrication of nanocones composed of other materials and applied to other applications, providing that the deposition process is compatible with the overall technological process.

The difference between the base of the nanocones in Figure 4 and Figure 6 can be explained by the different resolutions used to fracture the circles. For the study of the mask diameter variation, we used a higher resolution ( $1 \mathrm{~nm}$ instead of $5 \mathrm{~nm}$ ) in order to be more accurate. As the beam is a Gaussian beam of $\sim 5-10 \mathrm{~nm}$ (and not $1 \mathrm{~nm}$ ), this fracturing method leads to a small increase of the diameter of the written circle. This is demonstrated in Figure 7, assuming a beam size of $5 \mathrm{~nm}$, all the circles will be written with $4 \mathrm{~nm}$ more.

(a)

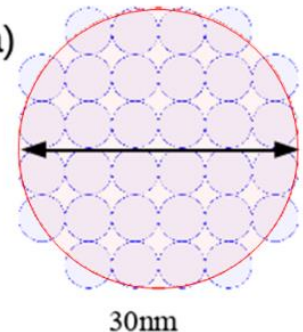

(b)

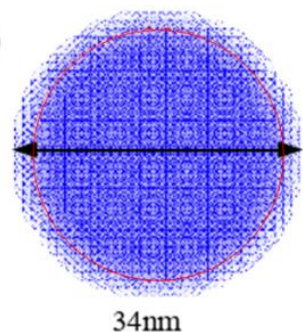

(c)

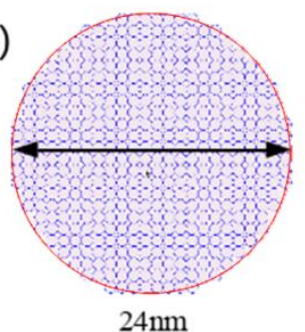

(d)

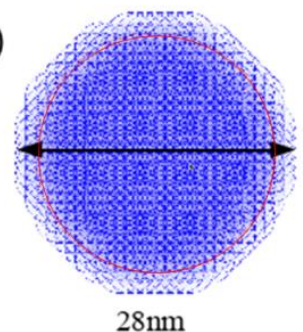

Figure 7. Schematic diagrams showing the fracturing of $30 \mathrm{~nm}$ and $24 \mathrm{~nm}$ circles with different resolutions during ebeam writing. (a) A $30 \mathrm{~nm}$ diameter circle (red) fractured with a $5 \mathrm{~nm}$ resolution (black circles represent a $5 \mathrm{~nm}$ beam size). (b) A $30 \mathrm{~nm}$ diameter circle (red) fractured with a $1 \mathrm{~nm}$ 
resolution (black circles represent a $5 \mathrm{~nm}$ beam size). (c) A $24 \mathrm{~nm}$ diameter circle (red) fractured with a $1 \mathrm{~nm}$ resolution (black circles represent a $1 \mathrm{~nm}$ beam size). (d) A $24 \mathrm{~nm}$ diameter circle (red) fractured with a $1 \mathrm{~nm}$ resolution (black circles represent a $5 \mathrm{~nm}$ beam size).

Let us now look at how our experimental results compare to modelling of the deposition via a shadow mask.

\subsection{Comparison of experimental results with a deposition model}

The deposition of the nanocones, by evaporation passing via a shadow mask, can be modelled using an analytical approach [47]. The model considers the rotation of the sample, the amount of tilt of the sample, and the vertical and horizontal deposition rates of the evaporated material onto the mask itself. It is these latter factors which lead to the gradual closing of the mask opening during the deposition of the evaporated matter - this causes the formation of cone-like topographic features. This deposition model enables a prediction of the vertical profile thickness $t(x)$ of the nanocone as a function of distance along the base radius $x$. The dimensions and overall profiles of the experimentally-derived gold nanocones fabricated in the study can therefore be compared to the predictions of this model. Figure 8 shows examples of the profiles which can be computed using the model.
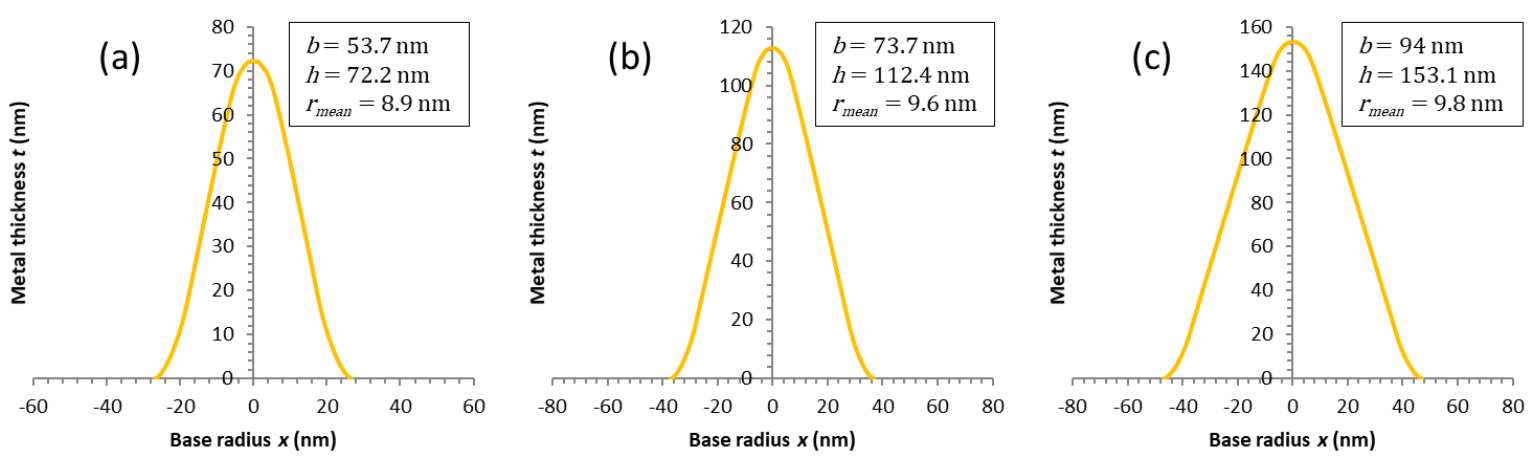
Figure 8. Predicted nanocone thickness profiles as a function of length across the base obtained using the deposition model [47]. The initial mask opening is (a) $45 \mathrm{~nm}$, (b) $65 \mathrm{~nm}$, and $85 \mathrm{~nm}$. The sample is tilted at an angle of $0.5^{\circ}$ with respect to the evaporation source. The sample is considered to be rotated during the deposition — and completing at least one full revolution. The vertical deposition parameter is taken to be unity, and the horizontal growth parameter on the mask is taken to be 0.24 .

In order to generate the nanocone profiles shown in Figure 8 the initial mask opening diameters used in the modelling are equal to $45 \mathrm{~nm}$ [Fig. 8(a)], $65 \mathrm{~nm}$ [Fig. 8(b)], and $85 \mathrm{~nm}$ [Fig. 8(c)]. For the modelling, the sample is considered to be tilted at an angle of $0.5^{\circ}$ with respect to the evaporation source perpendicular. This angle is chosen as the manufacturers of the evaporation system give a tilt precision error of $\pm 0.5^{\circ}$. The sample is also considered to be rotated during the deposition-completing at least one full revolution to achieve a symmetrical cone about its central vertical axis. The vertical deposition parameter is taken to be unity, and the horizontal growth parameter on the mask is taken to be 0.24 . By varying the initial mask opening in the model, the solid red line plots shown in Figure 6 can be obtained. First, it can be observed that the model predicts the trends of the experimental profiles of the fabricated nanocones - details such as the rounding at the cone base, the quasi-straight sidewalls, and the rounded tips are all predicted. Second, the model can predict the specific dimensions of the fabricated nanocones. For a given base diameter, the vertical height of the cone is accurately predicted. The modelling also enables the lateral growth coefficient (at the small evaporation deposition angle $<1^{\circ}$ here) to be giventhe modelling and experimental results give a value near to 0.24 .

We can compare the predictions of the model with gold nanocones fabricated by Kontio et al [7]. This group fabricated highly conic-like features having a base diameter of $130 \mathrm{~nm}$ and a height of $257 \mathrm{~nm}$ - the model used here accurately predicts these dimensions. Although it should be noted that by using other materials, in particular aluminium, Kontio et al [7] clearly demonstrate that the granularity of the evaporative deposition determines the likeness to a conical structure. 
Let us now try to explain the vestiges of evaporated matter observed in proximity to the base of the nanocones. This is apparent on some of the SEM images of the smaller nanocones. As well as the computing the profile of the evaporated matter, the deposition model is also able to compute the amount of evaporated material deposited onto the sidewalls of the lithographic lift-off feature. For the small evaporation tilt angle considered here, the thickness of this deposition is $<1 \mathrm{~nm}$. In reality, this corresponds to a non-uniform deposition of gold [71]. In practice, when the resist lift-off step is preformed, this sidewall deposition can remain in proximity to the main conical feature. This effect is more apparent at higher evaporation tilt angles [30], where the sidewall deposition is thicker and becomes uniform. As the undercut in the bilayer resist is known to be less for smaller openings [30], sidewall deposition — and hence the possibility of its resulting vestiges in proximity to features —is likely to be more prevalent on smaller resist openings due to less shadowing.

Now let us focus on the rounding of the apex of the nanocones observed in the SEM images. The 'sharpness' of such features is important in certain applications. First, the sharpness of the tip governs the special resolution of near field microscopies, e.g. atomic force microscopy (AFM). Second, the sharpness of tips determines the electric field enhancement introduced by such features, this is important in tip-enhanced Raman spectroscopy (TERS). In terms of the shape of the apex of the nanocones, the deposition model predicts a non-circular tip shape, whereas a circular tip shape was assumed as a first approximation in the analysis of the SEM images - see Fig. 3. Despite this, we can still compare these values by first computing and plotting the radius of curvature of the nanocone apex from the modelling of the profile. As the model [47] enables one to plot the predicted vertical nanocone height $h$ as a function of its base radius $r$, the following equation is used to calculate the curvature $\kappa$ of the profile $t(x)$ :

$$
\kappa=\frac{\frac{d^{2} t}{d x^{2}}}{\left(1+\frac{d t^{2}}{d x}\right)^{\frac{3}{2}}}
$$

This can be performed numerically on the $t(x)$ data generated by the model. Once the curvature is computed, the curvature radius $r_{c}=1 / \kappa$ can be plotted as a function of nanocone base variable $x$-see 
Figure 9. In order to make a comparison with the experimentally-derived tip radii, one can calculate the mean of the computed tip curvature - these values are given in Table I. It is apparent from Fig. 9 that the radii of curvature $r_{c}$ increases rapidly with $x$, therefore the mean radius of curvature is calculated in the proximity of the tip for values of $r_{c}$ less than $60 \mathrm{~nm}$. In addition, the geometric mean of is employed to reduce the effect of large values in the data range. The calculated values of $r_{\text {mean }}$ correspond well with the values of circular tip radius $r$ which were extracted from the SEM images. The measured and predicted tip curvature agrees well with the observations of Kontio et al [6] who measured nanocones having a $10 \mathrm{~nm}$ tip radius. One can also note that as the model does not predict a circular-like tip, one can give values for the minimum radius of curvature $r_{c}^{x=0}$ of a modelled cone. For the evaporation parameters used here, the model predicts values for this $<2 \mathrm{~nm}$-although it must be remembered that the model does not take into account the granularity of the deposition-which, depending on the material, is known to be a factor determining the sharpness of a nanocone made using these means [7]. Other higher-resolution methods, e.g. transmission electron microscopy, would be needed to investigate the true nature of the apex of the nanocones.
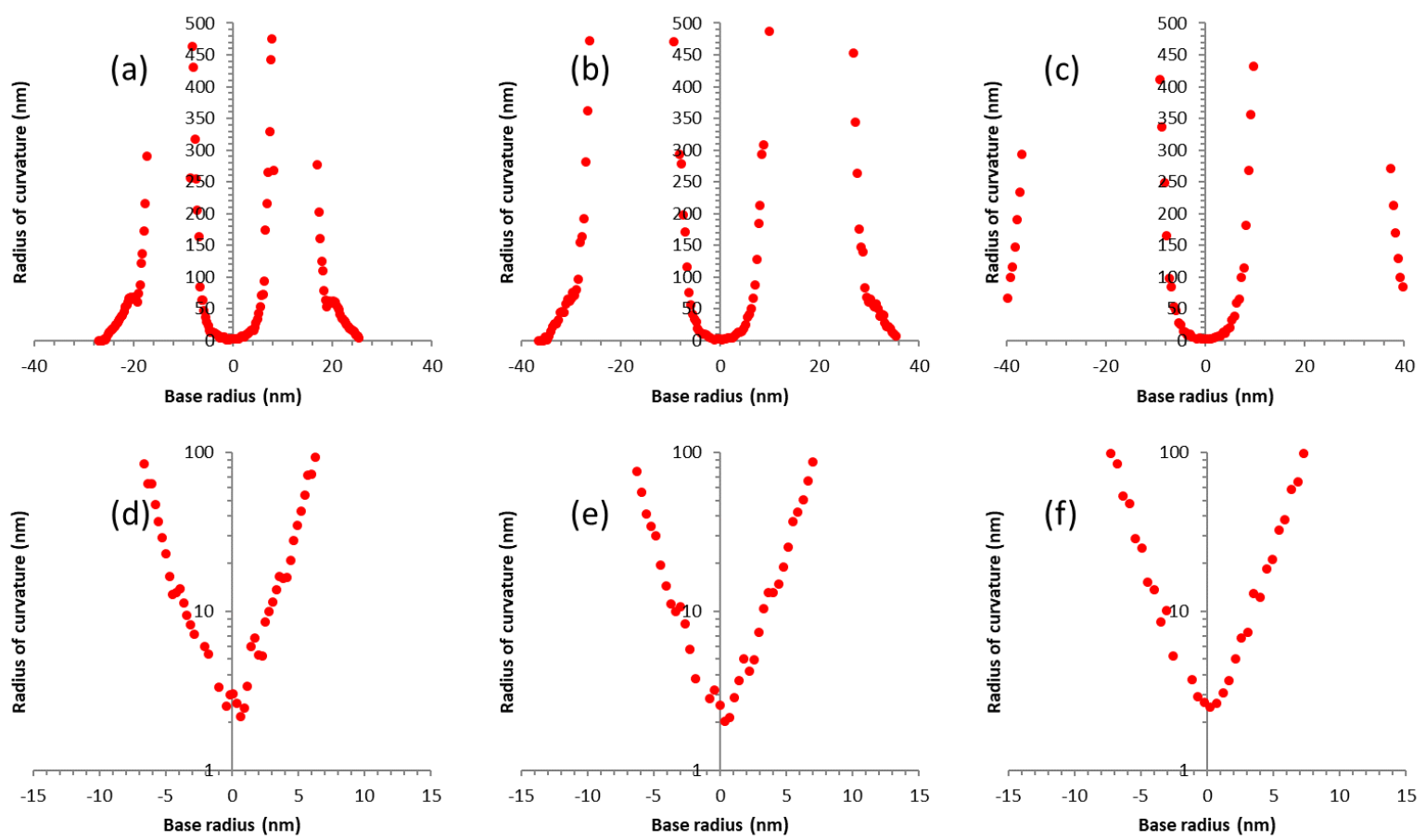
Figure 9. Plots of the calculated radii of curvature obtained from the modelled nanocone profiles. The initial mask opening is (a) and (d) $45 \mathrm{~nm}$, (b) and (e) $65 \mathrm{~nm}$, and (c) and (f) $85 \mathrm{~nm}$. The sample is tilted at an angle of $0.5^{\circ}$ with respect to the evaporation source perpendicular. The sample is considered to be rotated during the deposition - and completing at least one full revolution. The vertical deposition parameter is taken to be unity, and the horizontal growth parameter on the mask is taken to be 0.24 .

Table 1. Experimental and modelled nanocone tip radii. The experimental tip radius is obtained by geometric fitting of the SEM images of fabricated nanocones. The value of $r_{\text {mean }}$ is obtained from the deposition modelling. $r_{c}^{x=0}$ is the value of the radius of curvature at the tip of the modelled nanocone.

\begin{tabular}{cccc}
\hline Base diameter $\boldsymbol{b}(\mathbf{n m})$ & Experimental tip radius $\boldsymbol{r}(\mathbf{n m})$ & Modelled $\boldsymbol{r}_{\text {mean }}(\mathbf{n m})$ & Modelled $\boldsymbol{r}_{\boldsymbol{c}}^{\boldsymbol{x}=\mathbf{0}}(\mathbf{n m})$ \\
\hline 54.7 & $9.7 \pm 1.3$ & 8.9 & 1.5 \\
73.9 & $9.1 \pm 1$ & 9.6 & 1.8 \\
94 & $9.6 \pm 2$ & 9.8 & 2.1
\end{tabular}

\section{Conclusions}

Metallic nanocones having base diameters $<100 \mathrm{~nm}$ can be manufactured by combining electron beam lithography, ebeam evaporation, and lift-off. Precise dimension control of gold nanocones is achieved using the method. Gold nanocones can be fabricated having a base diameter varying from $53.6 \pm 2.1 \mathrm{~nm}$ to $94.1 \pm 2.4 \mathrm{~nm}$, a vertical height ranging from $71.3 \pm 4.1 \mathrm{~nm}$ to $153.4 \pm 3.4 \mathrm{~nm}$, and an apex radius of curvature of ranging from $8.4 \pm 1.2 \mathrm{~nm}$ to $11.6 \pm 1.5 \mathrm{~nm}$. The results of the fabrication compare well with the predictions of a deposition model which considers the evolving shadow masking during the deposition of the gold to compute the nanocone profile. Being a lithographic-based process using common resists and processing, we conclude that the process is readily integrable into a larger micro/nanotechnological process such as micro/nanoelectromechanical systems (MEMS/NEMS) fabrication processes. It enables the reproducible fabrication of both accurately positioned isolated nanocones and large, dense arrays of identical nanocones - meaning that the approach can be used for 
a wide range of applications. We also note that the controlled lithographic/lift-off process demonstrated here could - at least in principle — be applied for the fabrication of nanocones composed of other materials. Providing that the deposition process is compatible with the overall technological process. It is our hope that both researchers and engineers working in several areas should find the findings useful and easily applicable.

\section{Acknowledgements}

We acknowledge financial support from the Hauts-de-France region of France for contracts DOS0025370/00 and 17007720, and from the French Angence National de la Recherche (ANR) for contract ANR-16-CE09-0029. One of the authors (D. E.) acknowledges financial support from the French Association National Recherche Technologie (ANRT) for a Conventions Industrielles de Formation par la Recherche (CIFRE) grant N²015/0803. The authors would like to thank Annie Fattorini (Engineer at IEMN) for her invaluable technical help with the metallisation. The work has, in part, been performed using the facilities of the French RENATECH network. D.E. is now at the Institute of Materials Research and Engineering (IMRE), 2 Fusionopolis Way, Singapore.

\section{ORCID iDs}

Thierry Mélin http://orcid.org/0000-0003-1777-3512

Steve Arscott https://orcid.org/0000-0001-9938-2683

\section{References}

[1] Stade F, Heeren A, Fleischer M and Kern D P 2007 Fabrication of metallic nanostructures for investigating plasmon-induced field enhancement Microelectron. Eng. 84 1589-92

[2] Sexton L T, Horne L P and Martin C R 2007 Developing synthetic conical nanopores for biosensing applications Mol. Biosyst. 3 667-85

[3] Kim T, Kim J, Son S J and Seo S 2008 Gold nanocones fabricated by nanotransfer printing and their application for field emission Nanotechnology 19295302 
[4] Fleischer M, Stanciu C, Stade F, Stadler J, Braun K, Heeren A, Häffner M, Kern D P and Meixner A J 2008 Three-dimensional optical antennas: Nanocones in an apertureless scanning near-field microscope Appl. Phys. Lett. 93111114

[5] Fleischer M, Stade F, Heeren A, Häffner M, Braun K, Stanciu C, Ehlich R, Hörber J K H, Meixner A J and Kern D P 2009 Nanocones on transparent substrates for investigations in scanning probe microscopes Microelectron. Eng. 86 1219-21

[6] Kontio J M, Husu H, Simonen J, Huttunen M J, Tommila J, Pessa M and Kauranen M 2009 Nanoimprint fabrication of gold nanocones with $\sim 10 \mathrm{~nm}$ tips for enhanced optical interactions Opt. Lett. 34 1979-81

[7] Kontio J M, Simonen J, Tommila J and Pessa M 2010 Arrays of metallic nanocones fabricated by UV-nanoimprint lithography Microelectron. Eng. 87 1711-5

[8] Zhang Y, Santhanam S, Liu J and Fedder G K 2010 Active CMOS-MEMS AFM-like conductive probes for field-emission assisted nano-scale fabrication 2010 IEEE 23rd International Conference on Micro Electro Mechanical Systems (MEMS) (Wanchai, Hong Kong, China: IEEE) pp 336-9

[9] Zeeb B, Jäger S, Schäfer C, Nill P, Meixner A J, Kern D P and Fleischer M 2010 Self-aligned gold nanocone probe tips J. Vac. Sci. Technol. B Nanotechnol. Microelectron. Mater. Process. Meas. Phenom. 28 C6O34-C6037

[10] Fleischer M, Weber-Bargioni A, Altoe M V P, Schwartzberg A M, Schuck P J, Cabrini S and Kern D P 2011 Gold Nanocone Near-Field Scanning Optical Microscopy Probes ACS Nano 5 2570-9

[11] Coppé J-P, Xu Z, Chen Y and Logan Liu G 2011 Metallic nanocone array photonic substrate for high-uniformity surface deposition and optical detection of small molecules Nanotechnology 22 245710

[12] Di D, Dong P, Chen J, Chen J, Zhou Z, Wu X and Li S 2011 Inexpensive and fast fabrication of ordered gold nanocone arrays 2011 6th IEEE International Conference on Nano/Micro Engineered and Molecular Systems 2011 IEEE International Conference on Nano/Micro Engineered and Molecular Systems (NEMS) (Kaohsiung, Taiwan: IEEE) pp 555-8

[13] Ikegami M, Mie Y, Hirano Y, Suzuki M and Komatsu Y 2011 Size-controlled fabrication of gold nanodome arrays and its application to enzyme electrodes Colloids Surf. Physicochem. Eng. Asp. 384 388-92

[14] Fleischer M, Weber-Bargioni A, Cabrini S and Kern D P 2011 Fabrication of metallic nanocones by induced deposition of etch masks and ion milling Microelectron. Eng. 88 2247-50

[15] Chang W-Y, Lin K-H, Wu J-T, Yang S-Y, Lee K-L and Wei P-K 2011 Novel fabrication of an Au nanocone array on polycarbonate for high performance surface-enhanced Raman scattering $J$. Micromechanics Microengineering 21035023

[16] Liu Y, Du K, Wathuthanthri I and Choi C-H 2012 From nanocone to nanodisc: Structural transformation of gold nanoarrays via simple mechanical stresses J. Vac. Sci. Technol. B Nanotechnol. Microelectron. Mater. Process. Meas. Phenom. 30 06FF10

[17] Zhang P, He J, Ma X, Gong J and Nie Z 2013 Ultrasound assisted interfacial synthesis of gold nanocones Chem Commun 49 987-9 
[18] Toma M, Loget G and Corn R M 2013 Fabrication of Broadband Antireflective Plasmonic Gold Nanocone Arrays on Flexible Polymer Films Nano Lett. 13 6164-9

[19] Horrer A, Schäfer C, Broch K, Gollmer D A, Rogalski J, Fulmes J, Zhang D, Meixner A J, Schreiber F, Kern D P and Fleischer M 2013 Parallel Fabrication of Plasmonic Nanocone Sensing Arrays Small 9 3987-92

[20] Khan A D and Miano G 2013 Higher Order Tunable Fano Resonances in Multilayer Nanocones Plasmonics 8 1023-34

[21] Reichenbach P, Horneber A, Gollmer D A, Hille A, Mihaljevic J, Schäfer C, Kern D P, Meixner A J, Zhang D, Fleischer M and Eng L M 2014 Nonlinear optical point light sources through field enhancement at metallic nanocones Opt. Express 22 15484-501

[22] Fulmes J, Jäger R, Bräuer A, Schäfer C, Jäger S, Gollmer D A, Horrer A, Nadler E, Chassé T, Zhang D, Meixner A J, Kern D P and Fleischer M 2015 Self-aligned placement and detection of quantum dots on the tips of individual conical plasmonic nanostructures Nanoscale 7 14691-6

[23] Hoffmann B, Vassant S, Chen X-W, Götzinger S, Sandoghdar V and Christiansen S 2015 Fabrication and characterization of plasmonic nanocone antennas for strong spontaneous emission enhancement Nanotechnology 26404001

[24] Liu D, Wang Q, Hu J and Chen L 2016 Size correlation of optical and SERS properties for highly ordered Au nanocone arrays with sub-100 nm feature size J. Opt. 18085006

[25] Zhang L, Liu H, Chen L, Guan P, Chen B, Fujita T, Yamaguchi Y, Iwasaki H, Xue Q-K and Chen M 2016 Large-scale growth of sharp gold nano-cones for single-molecule SERS detection RSC Adv. $62882-7$

[26] Matsuzaki K, Vassant S, Liu H-W, Dutschke A, Hoffmann B, Chen X, Christiansen S, Buck M R, Hollingsworth J A, Götzinger S and Sandoghdar V 2017 Strong plasmonic enhancement of biexciton emission: controlled coupling of a single quantum dot to a gold nanocone antenna Sci. Rep. 742307

[27] Toma M, Belu A, Mayer D and Offenhäusser A 2017 Flexible Gold Nanocone Array Surfaces as a Tool for Regulating Neuronal Behavior Small 131700629

[28] Flatae A M, Tantussi F, Messina G C, Mohammadi A, De Angelis F and Agio M 2017 Plasmonic Gold Nanocones in the Near-Infrared for Quantum Nano-Optics Adv. Opt. Mater. 51700586

[29] Mannaris C, Teo B M, Seth A, Bau L, Coussios C and Stride E 2018 Gas-Stabilizing Gold Nanocones for Acoustically Mediated Drug Delivery Adv. Healthc. Mater. 71800184

[30] Eschimese D, Vaurette F, Troadec D, Leveque G, Melin T and Arscott S 2019 Size and shape control of a variety of metallic nanostructures using tilted, rotating evaporation and lithographic lift-off techniques Sci. Rep. 97682

[31] Eschimèse D, Hsia P, Vaurette F, Deresmes D, De Bettignies P, Schreiber J, Chaigneau M, Arscott S, Leveque G and Mélin T 2019 A Comparative Investigation of Plasmonic Properties between Tunable Nanoobjects and Metallized Nanoprobes for Optical Spectroscopy J. Phys. Chem. C 123 28392-400 
[32] Fulmes J, Schäfer C, Kern D P, Adam P-M and Fleischer M 2019 Relative spectral tuning of the vertical versus base modes in plasmonic nanocones Nanotechnology 30415201

[33] Li N, Dou S, Feng L, Wang X and Lu N 2019 Enriching analyte molecules on tips of superhydrophobic gold nanocones for trace detection with SALDI-MS Talanta 205120085

[34] Córdova-Castro R M, Krasavin A V, Nasir M E, Zayats A V and Dickson W 2019 Nanocone-based plasmonic metamaterials Nanotechnology 30055301

[35] Kawasaki D, Yamada H, Maeno K, Sueyoshi K, Hisamoto H and Endo T 2019 Core-ShellStructured Gold Nanocone Array for Label-Free DNA Sensing ACS Appl. Nano Mater. 2 4983-90

[36] Link S and El-Sayed M A 1999 Spectral Properties and Relaxation Dynamics of Surface Plasmon Electronic Oscillations in Gold and Silver Nanodots and Nanorods J. Phys. Chem. B 103 8410-26

[37] Jain P K, Lee K S, El-Sayed I H and El-Sayed M A 2006 Calculated Absorption and Scattering Properties of Gold Nanoparticles of Different Size, Shape, and Composition: Applications in Biological Imaging and Biomedicine J. Phys. Chem. B 110 7238-48

[38] Eustis S and El-Sayed M A 2006 Why gold nanoparticles are more precious than pretty gold: Noble metal surface plasmon resonance and its enhancement of the radiative and nonradiative properties of nanocrystals of different shapes Chem Soc Rev 35 209-17

[39] Amendola V, Pilot R, Frasconi M, Maragò O M and latì M A 2017 Surface plasmon resonance in gold nanoparticles: a review J. Phys. Condens. Matter 29203002

[40] Spindt C A 1968 A Thin-Film Field-Emission Cathode J. Appl. Phys. 39 3504-5

[41] Dolan G J 1977 Offset masks for lift-off photoprocessing Appl. Phys. Lett. 31 337-9

[42] Hatzakis M, Canavello B J and Shaw J M 1980 Single-Step Optical Lift-Off Process IBM J. Res. Dev. 24 452-60

[43] McCord M A and Pease R F W 1988 Lift-off metallization using poly(methyl methacrylate) exposed with a scanning tunneling microscope J. Vac. Sci. Technol. B 6293

[44] Chen W 1993 Fabrication of sub-10 nm structures by lift-off and by etching after electronbeam exposure of poly(methylmethacrylate) resist on solid substrates J. Vac. Sci. Technol. B Microelectron. Nanometer Struct. 11 2519-23

[45] Manfrinato V R, Zhang L, Su D, Duan H, Hobbs R G, Stach E A and Berggren K K 2013 Resolution Limits of Electron-Beam Lithography toward the Atomic Scale Nano Lett. 13 1555-8

[46] Dial O 1998 Fabrication of high-density nanostructures by electron beam lithography J. Vac. Sci. Technol. B Microelectron. Nanometer Struct. 16 3887-90

[47] Arscott S 2019 On evaporation via an inclined rotating circular lift-off shadow or stencil mask J. Vac. Sci. Technol. B 37 011602-12

[48] Kern W 1990 The Evolution of Silicon Wafer Cleaning Technology J. Electrochem. Soc. 137 1887-92 
[49] Heavens O S 1950 Some factors influencing the adhesion of films produced by vacuum evaporation J. Phys. Radium 11 355-60

[50] Schneider C A, Rasband W S and Eliceiri K W 2012 NIH Image to ImageJ: 25 years of image analysis Nat. Methods 9 671-5

[51] Homma Y 1985 Planar Deposition of Aluminum by RF/DC Sputtering with RF Bias J. Electrochem. Soc. 1321466

[52] Charlier J-C and Rignanese G-M 2001 Electronic Structure of Carbon Nanocones Phys. Rev. Lett. 86 5970-3

[53] Baylor L R, Merkulov V I, Ellis E D, Guillorn M A, Lowndes D H, Melechko A V, Simpson M L and Whealton J H 2002 Field emission from isolated individual vertically aligned carbon nanocones J. Appl. Phys. 91 4602-6

[54] Liu C, Hu Z, Wu Q, Wang X, Chen Y, Sang H, Zhu J, Deng S and Xu N 2005 Vapor-Solid Growth and Characterization of Aluminum Nitride Nanocones J. Am. Chem. Soc. 127 1318-22

[55] Cao L, Nabet B and Spanier J E 2006 Enhanced Raman Scattering from Individual Semiconductor Nanocones and Nanowires Phys. Rev. Lett. 96157402

[56] Chen I-C, Chen L-H, Ye X-R, Daraio C, Jin S, Orme C A, Quist A and Lal R 2006 Extremely sharp carbon nanocone probes for atomic force microscopy imaging Appl. Phys. Lett. 88153102

[57] Hsu C-M, Connor S T, Tang M X and Cui Y 2008 Wafer-scale silicon nanopillars and nanocones by Langmuir-Blodgett assembly and etching Appl. Phys. Lett. 93133109

[58] Qu C Q, Qiao L, Wang C, Yu S S, Zheng W T, Fu Y Z and Jiang Q 2008 First-principles densityfunctional calculations on the field emission properties of BN nanocones Solid State Commun. 146 399-402

[59] Yang N, Zhang G and Li B 2008 Carbon nanocone: A promising thermal rectifier Appl. Phys. Lett. 93243111

[60] Zhu J, Yu Z, Burkhard G F, Hsu C-M, Connor S T, Xu Y, Wang Q, McGehee M, Fan S and Cui Y 2009 Optical Absorption Enhancement in Amorphous Silicon Nanowire and Nanocone Arrays Nano Lett. 9 279-82

[61] Naess S N, Elgsaeter A, Helgesen G and Knudsen K D 2009 Carbon nanocones: wall structure and morphology Sci. Technol. Adv. Mater. 10065002

[62] Zhang S, Du Z, Lin R, Jiang T, Liu G, Wu X and Weng D 2010 Nickel Nanocone-Array Supported Silicon Anode for High-Performance Lithium-Ion Batteries Adv. Mater. 22 5378-82

[63] Sripirom J, Noor S, Köhler U and Schulte A 2011 Easily made and handled carbon nanocones for scanning tunneling microscopy and electroanalysis Carbon 49 2402-12

[64] Wang K X, Yu Z, Liu V, Cui Y and Fan S 2012 Absorption Enhancement in Ultrathin Crystalline Silicon Solar Cells with Antireflection and Light-Trapping Nanocone Gratings Nano Lett. 12 1616-9 
[65] Wang B and Leu P W 2012 Enhanced absorption in silicon nanocone arrays for photovoltaics Nanotechnology 23194003

[66] Saleem F, Zhang Z, Xu B, Xu X, He P and Wang X 2013 Ultrathin Pt-Cu Nanosheets and Nanocones J. Am. Chem. Soc. 135 18304-7

[67] Zhong D, Cai B, Wang X, Yang Z, Xing Y, Miao S, Zhang W-H and Li C 2015 Synthesis of oriented TiO2 nanocones with fast charge transfer for perovskite solar cells Nano Energy 11 409-18

[68] Qiu Y, Liu W, Chen W, Chen W, Zhou G, Hsu P-C, Zhang R, Liang Z, Fan S, Zhang Y and Cui Y 2016 Efficient solar-driven water splitting by nanocone BiVO ${ }_{4}$-perovskite tandem cells Sci. Adv. 2 e1501764

[69] Hazell G, Fisher L E, Murray W A, Nobbs A H and Su B 2018 Bioinspired bactericidal surfaces with polymer nanocone arrays J. Colloid Interface Sci. 528 389-99

[70] Zhang M, Fan H, Ren X, Zhao N, Peng H, Wang C, Wu X, Dong G, Long C, Wang W, Gao Y, Ma L, Wu P, Li H and Jiang X 2019 Study of pseudocapacitive contribution to superior energy storage of 3D heterostructure CoWO4/Co3O4 nanocone arrays J. Power Sources 418 202-10

[71] Messier R, Giri A P and Roy R A 1984 Revised structure zone model for thin film physical structure J. Vac. Sci. Technol. Vac. Surf. Films 2 500-3 